\title{
Fundamentos históricos metodológicos da pesquisa de campo em Geografia
}

\author{
Agostinho Paula Brito Cavalcanti*
}

\section{Resumo}

O presente artigo trata da fundamentação histórica e metodológica da pesquisa de campo em Geografia, realizada através dos precursores desta prática de ensino no âmbito do território nacional. Os métodos utilizados foram compostos pelo trabalho de gabinete, através de revisão bibliográfica para obtenção de informações pertinentes ao tema e análise dos dados. Como resultados foram catalogados $\mathrm{e}$ analisados as principais contribuições referentes às pesquisas práticas de campo publicadas no período compreendido entre 1940 e 2006. Como etapa conclusiva pode-se verificar que o período de 1940 a 1970, correspondeu a $52,2 \%$ do total dos trabalhos levantados. No período seguinte (1970-2000) correspondeu apenas a $17,3 \%$ e a partir de 2000 até 2006 foram catalogadas 30,5\% do total analisado, confirmando a retomada e uma maior valorização dessa prática nos cursos de Geografia.

Palavras-chave: Geografia; Metodologia; Pesquisa de campo.

Historical methodological fundamentals research field Geography

\section{Abstract}

This article deals with the historical and methodological fundamentals of field research in Geography, held by the

* Professor Doutor, Departamento de Geografia, Universidade Federal do Piauí (agos@ufpi.br).

Geosul, Florianópolis, v. 26, n. 51, p 39-58, jan./jun. 2011 
CAVALCANTI, A.P.B. Fundamentos históricos metodológicos da...

precursors of teaching practice within the national territory. The methods used were composed by the work of staff, through literature review to obtain information relevant to the subject and data analysis. The results were cataloged and analyzed the main contributions regarding the practical field research published in the period between 1940 and 2006. The conclusive phase can be seen that the period from 1940 to 1970 , accounted for $52.2 \%$ of studied papers. In the following period (1970-2000) accounted for just $17.3 \%$ and from 2000 to 2006 have been classified $30.5 \%$ of the total analyzed, confirming the recovery and a greater appreciation of the practice in Geography courses.

Key words: Geography, Methodology, Field research.

\section{Introdução}

O presente trabalho tem por objetivo apresentar os fundamentos históricos e metodológicos da pesquisa de campo em Geografia no âmbito do território brasileiro.

A pesquisa de campo é de importância fundamental para o avanço, ensino e aprendizagem da Geografia, além do peso de sua tradição histórica no pensamento geográfico, havendo um período recente, onde esse procedimento foi quase abandonado.

Ultimamente vem ocorrendo uma maior preocupação para a retomada dessa prática nos cursos de Geografia, tanto no Bacharelato quanto na Licenciatura no âmbito nacional. Esta preocupação atual pode ser atestada, pelo número de publicações voltadas especificamente para essa temática, bem como ter sido aprovada, nas novas grades curriculares, disciplinas que tem como objetivo principal fornecer aos acadêmicos, informações relativas à programação e à prática da pesquisa de campo.

Procurando contribuir para o revigoramento dos trabalhos práticos, com aferição da verdade terrestre, realizou-se um levantamento bibliográfico, fornecendo informações básicas seguida por comentários e análises sobre as obras de pesquisadores brasileiros 
CAVALCANTI, A.P.B. Fundamentos históricos metodológicos da...

e estrangeiros que efetivamente contribuíram para a consolidação da prática geográfica em nosso país. Foram selecionadas e levantadas publicações que dizem respeito à pesquisa de campo no contexto da Geografia brasileira, no período compreendido entre 1940 e 2006.

\section{Referencial histórico metodológico (1940-1970)}

$\mathrm{O}$ artigo de Delgado de Carvalho, intitulado " $A$ Excursão Geográfica" (CARVALHO, 1941) discute o sentido geográfico de "posição" e "situação", enfatizando a necessidade de se assimilar a consciência de espaço e de desenvolver a faculdade de observar as paisagens geográficas, a fim de que possam interpretá-las corretamente.

Em seguida discorre sobre a importância das excursões geográficas, pois irão despertar o interesse e o contato com a natureza, dando início ao processo de aprendizagem, equivalendo a muitas aulas teóricas em sala de aula. Também comenta e discute alguns pontos a respeito das excursões geográficas, que julga serem fundamentais, destacando os seguintes pontos: Preparo preliminar; Preparo psicológico; Organização da excursão; Observações dirigidas; Relatório de acadêmicos.

No que diz respeito aos aspectos físicos observa que é interessante levantar a topografia da região, os solos, a posição das camadas rochosas, trabalho das águas correntes, a vida vegetativa e a vida animal da área pesquisada. Possuindo então o observador, noções sobre a fisiografia da região, podem passar para o estudo da Geografia Humana e que denomina de estudo das comunidades.

No ano de 1943 apareceram duas publicações que se referem especificamente ao desenvolvimento de excursões geográficas. Uma delas é de autoria de José Veríssimo da Costa Pereira e intitula-se "Reflexão à margem de quatro excursões geográficas" (COSTA PEREIRA, 1943).

$\mathrm{O}$ autor inicia o texto enfatizando o extraordinário interesse que as excursões geográficas vêm despertando entre os geógrafos, nos últimos tempos, sendo este interesse fruto da orientação do 
CAVALCANTI, A.P.B. Fundamentos históricos metodológicos da...

ensino da Geografia. Segundo ele, a Geografia permanecia na rotina de decorar nomes que era o martírio e o espantalho dos acadêmicos, vítima do tipo de ensino que era posto em prática até então.

Comentou que nas excursões geográficas que tem tomado parte, pode verificar como fator de êxito das mesmas, o espírito de companheirismo e de franco desprendimento dos excursionistas, bem como tem havido sempre uma alegria sadia e jovial. Nas horas de cansaço, exaustão e desânimo, os participantes passavam a cantar músicas com letras adaptadas sobre assuntos geográficos ou temas ligados à excursão, evidenciando o verdadeiro espírito universitário, subjugando assim a rudeza do sertão.

A outra publicação de Lourenço Mário Prunes intitulado "Plano de estudo de uma excursão geográfica" (PRUNES, 1943), se inicia comentando que no ensino universitário, só recentemente tem havido a preocupação com a realização de excursões.

Procurando oferecer aos acadêmicos da faculdade, onde o ensino da Geografia constitui preocupação sadia e patriótica, uma formação científica de acordo com os elevados objetivos da Geografia moderna, permitindo um melhor conhecimento da terra brasileira e de seus habitantes forneceu uma série de dados, constantes de observações iniciais, notas e investigações outras.

"O trabalho de campo nas pesquisas originais de Geografia Regional" é o título do artigo publicado Francis Ruellan, então professor da Faculdade Nacional de Filosofia da Universidade do Brasil, no ano de 1944.

$\mathrm{O}$ autor inicia o texto afirmando que uma excursão geográfica de alunos do ensino primário não pode ter o mesmo programa e os mesmos métodos de uma excursão para alunos do curso secundário e muito menos para alunos de licenciatura.

Do mesmo modo, a excursão que tem por finalidade a pesquisa geográfica original, deve ter seus próprios métodos, pois cabe ao professor ensinar a um estudante adiantado ou mesmo a um jovem mestre, como se trabalha no campo, para chegar à descoberta de novas relações entre os fatos $\mathrm{e}$ as novas 
CAVALCANTI, A.P.B. Fundamentos históricos metodológicos da...

interpretações da Geografia Regional, podendo até tirar elementos para as comparações que são indispensáveis à Geografia Geral.

A organização desse tipo de excursão também é comentada afirmando que em primeiro lugar necessita-se agrupar os pesquisadores em equipe e que cada uma das equipes tem a responsabilidade de seu material e de suas observações, sendo dirigida por um chefe, assistida por um secretário.

Por fim, salienta que o êxito dessas excursões, está ligado a uma estrita disciplina a qual deve ser voluntariamente admitida pelos participantes e que sua exposição evidencie o fato de que é nesse tipo de empreendimento, que aparece a verdadeira tarefa do geógrafo, pois desde a origem da Geografia moderna, os grandes mestres não seguiam outro método a não ser este.

Delgado de Carvalho publica um artigo sobre a pesquisa de campo em Geografia, falando sobre o que se denomina de " $O$ Estudo da Paisagem" (CARVALHO, 1945).

Inicia o texto evidenciando que, enquanto a Geografia aparecer para o aluno secundário como uma disciplina que nada tem a ver com a vida diária ou um assunto deslocado da experiência prática, não poderá nunca despertar interesse, pois para ele, o exemplo por excelência, à situação concreta é a excursão geográfica.

Desse modo, afirma que não é de admirar que os professores, além de formar geógrafos, devem procurar sistematizar os conhecimentos indispensáveis à observação, ilustrando a sua argumentação com dois exemplos de observação que denomina do mais fecundo e mais moderno tipo de trabalho. Referindo-se a um trabalho anterior cita cinco pontos, a saber: preparo preliminar; preparo psicológico; organização da excursão; observação dirigida; relatórios.

Salienta então o que chama de observação dirigida, e que se destina a dar o sentido geográfico da "posição" e do "espaço", ao observador.

Comentando novamente o fato de que para vencer um obstáculo, insiste em subdividir as dificuldades, afirmando na sua visão que a primeira subdivisão que se impõe é distinguir uma parte da Geografia Física, chamada de parte condicionadora e de 
CAVALCANTI, A.P.B. Fundamentos históricos metodológicos da...

uma parte da Geografia Humana, chamada de parte condicionada. A seguir passa a enumerar os principais tópicos que devem ser levantados: i) A primeira noção a adquirir deve ser a de conjunto é a topografia da região que precisa ser analisada e definida; ii) A posição das camadas rochosas; iii) As águas correntes; iv) A vida vegetativa e a vida animal da zona em questão. Salienta que fica completa a fisiografia superficial da região estudada, podendo depois a empreender a interpretação antropogeográfica.

Nos trabalhos anteriores foi bastante comentado que quando da realização de um trabalho de campo é preciso de antemão saber exatamente o que observar. Em "As listas de fatos a observar nos trabalhos geográficos de campo" (STERNBERG, 1946) é o titulo do artigo publicado por Hilgard O. Sternberg, que discorre sobre esta questão. Para o autor a essência do autêntico trabalho geográfico consiste em: Observar; Registrar (e implicitamente localizar); Descrever e delimitar e Correlacionar e explicar os elementos constituintes da paisagem.

Considerando que as duas primeiras etapas se efetuam por excelência no campo, salienta que neste trabalho tratará principalmente da coleta de informações no campo.

Observa ainda que o plano deva ser preparado tendo em vista as condições particulares de cada região e que questionários ou listas de aspectos e fenômenos a observar já publicado em número considerável, geralmente apresentam um caráter generalizado.

Partindo do pressuposto que o fundamento geométrico da paisagem não foi levantado com muitos detalhes aproveita a oportunidade para incorporar o que denomina de esquema de observações de Passarge. Este esquema refere-se às características petrográficas do ponto de vista de sua influência geográfica, ou seja, de seus efeitos sobre as formas da superfície (resistência física e química das rochas).

Continuando a sua descrição, chama atenção para o fato de que não é só a parte física que pode ser tratada com mais detalhes, também os aspectos culturais se prestam a sucessivos desdobramentos e ainda o meio de transporte a ser empregado, que 
CAVALCANTI, A.P.B. Fundamentos históricos metodológicos da...

influi no planejamento do trabalho de campo, pois o horizonte de observações varia segundo o tipo de meio utilizado, sendo que os fatos observáveis apresentam diversidades regionais e variam de acordo com o modo pelo qual o observador se desloca.

Ao encerrar o artigo relata uma série de sugestões bibliográficas que podem ser consultadas quando da organização e preparo do trabalho de campo.

No ano seguinte Hilgard O. Sternberg publica outro artigo sobre essa temática sob o título: "O Trabalho de Campo na Geografia: seu planejamento e organização" (STERNBERG, 1947). Para se obter bons resultados nos trabalhos geográficos de campo são necessários três procedimentos, a saber: assegurar o preparo técnico do professor e dos acadêmicos; elaborar o programa de trabalho - determinando o fim visando, as etapas a serem vencidas e os meios empregados - e tomar as providencias administrativas preliminares e selecionar e preparar o equipamento necessário para a realização do trabalho de campo.

No que diz respeito à preparação técnica, é notório o fato das vantagens de se realizar uma excursão prévia a região a ser estudada, podendo o professor conhecer melhor a área e poder prever os problemas a serem enfrentados.

Também ressalta que os acadêmicos devem estar preparados psicologicamente para a realização do trabalho de campo, entendendo que ele não é uma atividade recreativa, devendo inteirar-se dos objetivos a serem atingidos e das dificuldades que irão enfrentar no campo.

Sobre essa excursão foi publicada uma série de relatórios preliminares e que recebeu o título de: "Trabalhos de campo e de gabinete da Segunda Expedição Geográfica ao Planalto Central” (GUIMARÃES, 1949).

Analisado o trabalho observa-se que está dividido em quatro itens principais. No item I é comentada a organização da expedição. No item II descrevem-se os itinerários que foram percorridos, os técnicos que participaram da expedição e os períodos de trabalho. No item III são descritas as normas de 
CAVALCANTI, A.P.B. Fundamentos históricos metodológicos da...

trabalho adotadas e por se tratar de um reconhecimento geográfico o método seguido foi a observação dos fatos que se apresentam seguida de sua interpretação, essenciais no trabalho geográfico.

$\mathrm{O}$ item IV denominado resultados preliminares comenta que os trabalhos de campo duraram quase três meses, sendo percorrida uma área de mais de $200.000 \mathrm{~km}^{2}$, resultando uma significativa quantidade de dados e que esse material seria cuidadosamente encaminhado e organizado para a elaboração do Relatório Final.

Como contribuição ao ensino de Geografia, Carlos M. Cantão publicou um texto intitulado: "Programa - Tipo de Excursões Geográficas para fins Didáticos” (CANTÃO, 1956). $\mathrm{Na}$ parte inicial discorre sobre a importância das excursões geográficas, enfatizando que para o ensino de Geografia desperte o interesse dos acadêmicos e tenha finalidade prática, deve ser realizado em contato direto com a natureza, pois o sentido da observação geográfica só é adquirido através das excursões.

Em seguida passa a discorrer sobre as dificuldades da organização das excursões, comentando sobre o problema da questão dos horários, das razões de ordem econômica e do tipo de estabelecimento de ensino, se é um colégio particular ou uma escola pública, cada uma apresentando suas dificuldades durante a realização das excursões.

Em seguida relata uma série de fatos geográficos começando pelos elementos do quadro natural e depois para o que denomina de elemento humano.

Sob o título de "Fases de Trabalho Educativo", considerada duas fases: a observação "in situ" e o relatório (exposição escrita do que foi verificado).

Finalizando descreve algumas zonas do Distrito Federal, para finalidade da realização de novos trabalhos, assim composta: Zona litorânea; Zona Agrícola e pastoril; Zona de Alagações e matas maritices; Zona urbana e Zona Industrial.

"Uma excursão aos arredores da cidade de São Paulo: Área de Cotia - Vargem Grande” (SEABRA 1965) é o titulo do trabalho publicado por Manoel Seabra, ressaltando que poderá servir de base 
CAVALCANTI, A.P.B. Fundamentos históricos metodológicos da...

para que os professores do ensino secundário ou superior possam planejar excursões de caráter geográfico. Ressalta que a saída em excursões com os alunos especialmente das escolas secundárias, oferece oportunidade para que o professor possa exemplificar e redefinir uma série de conceitos que tiveram em sala de aula.

Observando que o objetivo básico de uma excursão de caráter geográfico deve repousar sobre a interação de, através de paisagens, procurarem fazer chegar aos alunos à compreensão do arranjo do espaço, mostrando-lhes o quadro geográfico dentro de sua própria complexidade, procura traçar um roteiro de excursão onde apareçam os elementos fundamentais na organização do espaço.

Para tanto escolheu uma área nos arredores de São Paulo, a área de Vargem Grande - Cotia, que dista cerca de $40 \mathrm{~km}$ da capital e cujo objetivo principal foi procurar mostrar de que modo se manifesta, ao longo do trajeto, a influência da urbanização no arranjo da paisagem e que se estende sobre um raio de ação bastante significativo, afetando não só os fatos de ordem urbana (pequenas cidades próximas e subúrbios) como também os de ordem rural (atividades agrícolas, chácaras de fins de semana, etc.).

No ano de 1969 aparece outra publicação a respeito de roteiro de excursão, intitulado de "Roteiro de excursão à Araçatuba e Conjunto Hidrelétrico de Urubupungá” (MACEDO, 1969), onde procura atingir os seguintes objetivos: sugerir aos professores uma área-objetivo para excursão e transmitir, especialmente aos professores de ensino secundário, a experiência de uma excursão à longa distância (cerca de $1.500 \mathrm{~km}$ de percurso, seis dias de duração e com significativo número de alunos).

Inicia o texto sugerindo e descrevendo detalhadamente o que denomina de "Plano de Trabalho" com essas idéias gerais: programar as atividades referentes à excursão; fazer da excursão uma atividade interdisciplinar; resolver os problemas referentes ao meio de locomoção; escolher as classes que serão convidadas; organizar uma comissão para coordenar a excursão; entregar para cada participante um caderno para anotações; dividir os alunos em 
CAVALCANTI, A.P.B. Fundamentos históricos metodológicos da...

grupos; realizar reuniões prévias com os alunos e após a excursão, apresentação dos relatórios.

Todas essas etapas programadas foram seguidas e cumpridas na excursão cujo objetivo principal foi à cidade de Araçatuba e áreas circunvizinhas e as obras do conjunto hidrelétrico de Urubupungá, nos limites entre os estados de São Paulo e Mato Grosso do Sul, no rio Paraná.

Conclui o trabalho afirmando que foi possível oferecer aos estudantes uma visão de conjunto de uma parte do território paulista, levando-os a estabelecer comparações, aguçando-lhes o sentido da observação e contribuindo para o aprimoramento da formação do educando.

\section{Referencial histórico metodológico (1970-2000)}

Em 1982, Armando Corrêa da Silva escreveu um artigo enfocando especificamente o trabalho de campo da Geografia Humana e que intitulou de "Natureza do Trabalho de campo em Geografia Humana e suas limitações” (SILVA, 1982) considerando três modalidades de conceito de campo em Geografia Humana e que são: os trabalhos analíticos empíricos; os trabalhos com enfoque lógico e a análise dialética epistemológica e ontológica, levantando em seguida alguns problemas relativos a esses conceitos.

Sob o subtítulo "Uma apresentação do tema" passa a conceituar o que é trabalho de campo e como ele foi realizado ou praticado por diferentes geógrafos, desde os mais tradicionais tais como Vidal de La Blanche, Ratzel, Hartshorne, até os mais modernos, Yves Lacoste, Milton Santos, M. Quaini, James Anderson e outros. Observa ainda, que na atualidade a Geografia Humana desenvolveu um raciocínio ontológico e epistemológico de caráter didático em várias vertentes e que o conceito de campo tornou-se uma entidade categorial, sendo o ponto de partida para a análise de espaço.

Em seguida comenta como se realiza o trabalho de campo dentro de cada uma das modalidades de "conceito de campo", que considerou no início do texto e que são: os trabalhos analíticos 
CAVALCANTI, A.P.B. Fundamentos históricos metodológicos da...

empíricos, os trabalhos com enfoque lógico e a análise dialética epistemológica e ontológica.

Um artigo sobre o trabalho de campo em Geografia foi publicado por Yves Lacoste, onde aborda questões pouco discutidas pelos geógrafos tais como: Qual a relação do pesquisador com seu objeto de estudo e como deve ser organizado um trabalho de pesquisa?

Intitula seu artigo de "A Pesquisa e o Trabalho de Campo: um problema politico para os pesquisadores, estudantes $e$ cidadãos" (LACOSTE, 1985). No início do texto já evidencia que esse trabalho é consagrado aos problemas da pesquisa e do campo e que o mesmo não é direcionado para enumerar receitas metodológicas, mas para colocar um determinado número de problemas que raramente são citados pelos pesquisadores frente aos que estudam e cujo território analisa (os caracteres físicos). Mas o problema também diz respeito aos cidadãos sobre os quais recaem as pesquisas, pois elas (as pesquisas) podem ter as mais diversas conseqüências para a população estudada.

Em um trecho de seu artigo que denomina de "Por uma transformação democrática da relação de pesquisa", discute e evidencia toda a problemática da responsabilidade do pesquisar frente ao seu objeto de estudo e como devem ser organizadas e realizadas essas pesquisas.

Finalizando comenta que o campo é uma prática indispensável, mas não suficiente e que é preciso haver um esforço para modificar as relações entre os pesquisadores e pesquisados, onde a população alvo deve ter consciência do produto final das pesquisas realizadas, a fim de poderem tomar parte nos projetos que lhes interessam.

Nesse mesmo ano, Bernard Kayser, publicou um artigo especificamente voltado para o trabalho de campo, intitulado: " $O$ Geógrafo e a Pesquisa de Campo” (KAYSER, 1985).

Partindo de uma frase de Mao Tse-tung que diz: "Sem pesquisa de campo ninguém tem direito a falar”, comenta que não há como não tirar dessa interpretação, uma reflexão profunda sobre o estatuto político do pesquisador e da pesquisa. Salienta também que na revista 
CAVALCANTI, A.P.B. Fundamentos históricos metodológicos da...

Hérodote bem como em outras revistas, já apareceram muitos trabalhos sobre essa temática, onde foram realizadas análises sobre esse assunto, mas de maneira um tanto quanto parciais.

Propõe então, logo em seguida, o que espera de seu artigo, ou seja, diz que gostaria que o mesmo fosse claro, politicamente definido, conduzindo a conclusões susceptíveis de guiar à ação do pesquisador levantando ao mesmo o tempo a seguinte questão: Mas será que conseguiremos?

Para ele a sua dúvida vem do tipo de sociedade que estamos vivenciando nos dias atuais uma sociedade capitalista de consumo, onde os universitários refletem o sistema atual, nas suas condutas e contradições.

Após expor seu pensamento a respeito desses temas o autor conclui que de fato a prática e o uso da pesquisa de campo são penosos, mas sem pesquisa de campo?

Pretendendo discutir o trabalho de campo ou mais especificamente o levantamento empírico como potencialidade para a ampliação do rigor das investigações a respeito do momento que estamos vivendo e a observação participante, Roosevelt J. Santos redigiu o artigo intitulado: "Pesquisa empírica e trabalho de campo: algumas questões acerca do conhecimento geográfico" (SANTOS, 1999).

No texto observa ser muito importante reconhecer o conhecimento geográfico como um processo, aceitar o fato de que o mesmo depende de outras ciências e de teorias não geográficas e que essa dependência faz parte da Geografia, sendo, portanto indispensável encaminhar e discutir os meios de enriquecer o conhecimento geográfico.

Argumentando que o trabalho de campo é um instrumento didático-pedagógico do ensino da Geografia, Antonia B. Rodrigues e Cláudia A. Otaviano escreveram um artigo onde procuram destacar a importância deste recurso pedagógico no processo de ensino e aprendizagem em Geografia, apresentando, ainda, um conjunto de orientações para o planejamento e desenvolvimento do mesmo. 
CAVALCANTI, A.P.B. Fundamentos históricos metodológicos da...

Esse trabalho intitula-se "Guia Metodológico de Trabalho de Campo em Geografia” (RODRIGUES \& OTAVIANO, 1991) e na introdução comentam que abordar essa temática de maneira mais profunda é tarefa muito difícil, em virtude da escassa bibliografia existente sobre essa temática e principalmente no que se refere a uma bibliografia mais atualizada. Salientam que a maioria dos estudos já realizados referiu-se preferencialmente a respeito do trabalho de campo, enquanto métodos de ensino.

Considerando que o trabalho de campo em sua forma e essência é um método relevante dentro do planejamento de ensino ou em sua prática propriamente dita, aos autores discorrem primeiramente sobre essa problemática, enfocando logo em seguida o que denominam de "As orientações pedagógicas relevantes para organização de um trabalho de campo".

Finalizando ressaltam que o trabalho de campo é o prolongamento das aulas teóricas, sendo uma atividade importante e como tal considerada no contexto específico da avaliação contínua e de referência, ressaltando o papel do docente que deve colocar toda sua potencialidade e criatividade na realização deste trabalho.

\section{Referencial histórico metodológico (2000 - 2006)}

Em "Trabalho de campo: limites e contribuições para a pesquisa geográfica” (DAVID, 2002) enfatiza que tanto a observação como o trabalho de campo sempre teve destaque na Geografia, sendo o objetivo procurar discutir essa situação demonstrando problemas do método indutivo; os limites da observação como ponto de partida para a investigação e em que medida o trabalho de campo pode ser útil na pesquisa geográfica.

Discute a respeito do método indutivo na Geografia e a observação relatada no subtítulo: "Para enxergar além de ver" e a questão do trabalho de campo como processo de investigação geográfica, envolvendo a relação entre o cientista e o objeto pesquisado.

Por fim, no subtítulo "Para não encerrar as questões", evidencia algumas posições que devem ficar claras no 
CAVALCANTI, A.P.B. Fundamentos históricos metodológicos da...

desenvolvimento do trabalho de campo, bem como quais são os cuidados que deve ser tomado durante o processo de pesquisa, que envolve uma relação dialógica ou uma relação entre o pesquisador e o investigado, que tanto pode ser um grupo humano com uma porção de espaço terrestre.

Outro artigo intitula-se "Trabalho de campo: prática “andante” de fazer Geografia" (RADAELLI DA SILVA, 2002). $\mathrm{Na}$ introdução a autora explica como foi elaborado esse texto, evidenciando que o mesmo está ancorado em algumas idéias básicas sobre trabalho de campo (e que denominam de prática "andante" de fazer Geografia), bem como esclarece que procurou adotar, nesse trabalho, uma visão baseada na análise neomarxista da teoria e da prática educacional.

Conduzindo o seu texto salienta que as idéias e questões que foram colocadas neste trabalho, foram produtos de uma história de vivência e de experiências pessoais, estruturada coletivamente no diálogo de quem ensina com aqueles que aprendem, procurando expressar no texto uma preocupação, um compromisso e um desafio.

O trabalho "Uma Proposta para a formação de professores de Geografia: trabalho de campo integrado" (ANTONELLO; MOURA; TORRES, 2005), cujo objetivo principal é apresentar uma experiência de ensino, traduzidas na prática por meio da realização de um trabalho de campo integrado, possibilitando a atuação conjunta de professores responsáveis pelas diversas disciplinas.

Os autores colocam que o intuito da realização desta prática pedagógica é também relacionar com a teoria com a prática pedagógica é também relacionar a teoria com a prática, na construção do conhecimento geográfico, bem como apresentar os resultados obtidos através do trabalho de campo. Enfatizam que o trabalho de campo é de significativa importância como complemento das aulas teóricas e que os discentes envolvidos e futuros profissionais tiveram a oportunidade de problematizar a realidade conseguindo obter informações a partir da pesquisa empírica.

Após o desenvolvimento do texto concluem realçando que essa prática pedagógica foi bastante significativa possibilitando 
CAVALCANTI, A.P.B. Fundamentos históricos metodológicos da...

demonstrar à importância de se considerar a realidade concreta, baseada em uma fundamentação teórica e que nas diversas etapas do trabalho de campo houve oportunidade para o aprofundamento de questões referentes à relação teoria e prática, bem como possibilitou a construção de conhecimentos essenciais para a formação docente.

Outra significativa obra foi organizada por Luis Antonio Bittar Venturi e intitula-se "Praticando Geografia - Técnicas de Campo e Laboratório” (VENTURI, 2005).

$\mathrm{Na}$ apresentação do Prof. Carlos Augusto de Figueiredo Monteiro, é ressaltada a importância do livro, no momento atual que está atravessando a Geografia brasileira, onde são valorizadas as técnicas de análise, as quais, por sua vez sofreram progressos nos últimos anos e, portanto vem enriquecer o processo de formação dos jovens geógrafos brasileiros.

Outra obra foi publicada por Adler Guilherme Viadana e intitulada "A excursão Geográfica Didática (Pontal do Triângulo Mineiro)" (VIADANA, 2005). Na introdução explica que a finalidade do mesmo é apresentar as interpretações de campo, a partir da realização de uma excursão didática. Em seguida passa a declinar os objetivos pretendidos na finalização das atividades de ensino/aprendizagem, ressaltando que para atingi-los, baseou-se no conteúdo programático da disciplina Geografia do Brasil, fornecendo os títulos dos temas abordados em uma bibliografia básica para nortear este estudo.

Publicamos em 2006 o livro intitulado "Métodos e Técnicas da Pesquisa Ambiental - Guia para estudos no meio ambiente" (CAVALCANTI, 2006). Nas considerações iniciais ressaltamos o problema da civilização contemporânea e seu comprometimento com a degradação ambiental e a diminuição da qualidade de vida das populações, observando que a formação de uma consciência ambiental depende principalmente de uma ampla e persistente pesquisa cientifica, juntamente com uma efetiva ação educativa. Portanto, esta obra serve de guia para os estudos do meio ambiente, podendo ser útil para os acadêmicos de graduação e pós-graduação 
CAVALCANTI, A.P.B. Fundamentos históricos metodológicos da...

ligados ao estudo do meio ambiente que estão se iniciando nessa temática.

Comentamos sobre a importância da análise ambiental e a elaboração de métodos integrados de pesquisa e afirmamos que o presente trabalho tem como meta principal, discorrer sobre os aspectos metodológicos da análise ambiental e nos preocupamos com uma avaliação dos principais métodos e técnicas para o estudo do meio ambiente. Dividimos o texto em 10 capítulos, expondo a temática abordada da seguinte forma: Características e natureza da ciência; Evolução histórica da análise ambiental: o papel da Ecologia, Biogeografia e da Geografia Física; a abordagem sistêmica e o estudo da paisagem; Métodos de análise ambiental; Aplicação de metodologias e técnicas de pesquisa: Procedimentos metodológicos e técnicas de pesquisa; Prática da pesquisa ambiental; Roteiro de pesquisas ambientais; Desenvolvimento e elaboração de projetos de pesquisas ambientais; Roteiro metodológico para pesquisa de campo - Aferição da verdade terrestre; Aplicação de métodos em pesquisas ambientais e Técnicas empregadas nos estudos ambientais: Quantificação; Modelagem de sistemas ambientais; Sensoriamento Remoto e Geoprocessamento.

\section{Conclusões}

A abordagem histórica metodológica da Geografia é extremamente complexa, sendo tratada uma variedade de concepções, todas relevantes para afirmação desta ciência. Pode-se vislumbrar a possibilidade de recriar uma abordagem que integre conceitos, métodos e técnicas dos setores distintos, no sentido de gerar uma metodologia que seja capaz de abranger alternativas de utilização, com a manutenção da harmonia entre o meio ambiente e o processo de desenvolvimento.

No que diz respeito às publicações pode-se verificar as seguintes conclusões: de 1940 a 1970, portanto num período de trinta anos, foram levantados 12 artigos relativos à pesquisa de 
CAVALCANTI, A.P.B. Fundamentos históricos metodológicos da...

campo em Geografia e que corresponde a 52,2\% do total, portanto, mais da metade dos trabalhos levantados.

Até por volta de 1970, predominou na Geografia brasileira a escola francesa, desenvolvida por Vidal de La Blache e seus discípulos, onde a prática de campo, traduzindo no estudo das paisagens e na Geografia regional, era bastante valorizada e a preocupação com a sua divulgação.

No período seguinte, de 1970 a 2000, e que também corresponde a um período de 30 anos, teve-se apenas quatro publicações, correspondendo a 17,3\%. Isto pode ser justificado, pois nessa época foi o apogeu da Geografia Quantitativa no Brasil, cujos dois pólos foram o Instituto Brasileiro de Geografia e Estatística (IBGE) no Rio de Janeiro e o Curso de Geografia da Universidade Estadual Paulista (UNESP) de Rio Claro - São Paulo, vindo atestar o desprezo da maioria dos geógrafos pela prática de campo e o pouco interesse na publicação de trabalhos dessa natureza.

A partir de 2000, pode-se notar que está havendo uma maior preocupação com a prática e valorização do trabalho de campo em Geografia, foi de 2000 a 2006, num período de apenas seis anos, foram levantados sete trabalhos publicados, perfazendo $30,5 \%$ do total e sendo que aparecem, pela primeira vez, três livros textos específicos para a pesquisa de campo.

Finalizando pode-se afirmar, com base nos dados e informações levantadas, que realmente está havendo, nos últimos anos, uma maior preocupação e valorização dessa prática, nos cursos de Geografia a âmbito nacional. Também se afirma que o intuito do presente trabalho foi contribuir a esse empreendimento, procurando-se ressaltar a importância da pesquisa de campo em Geografia, discutir a respeito da dependência da observação cientifica e realizar um breve comentário bibliográfico de artigos e livros, para que os acadêmicos de graduação e de pós-graduação possam tomar conhecimento do que foi publicado sobre a temática em questão. 
CAVALCANTI, A.P.B. Fundamentos históricos metodológicos da...

\section{Referências bibliográficas}

ANTONELlO, I. T.; MOURA, J. D. P.; TORRES, E. C. Uma proposta para a formação de professores de Geografia: trabalho de campo integrado. Geografia, Rio Claro: v. 30, n 3, p.471-490, 2005.

CANTÃO, C. M. Programa - Tipo de excursões geográficas para fins didáticos. Boletim Geográfico. Rio de Janeiro: ano XIV, $\mathrm{n}^{\mathbf{o}}$ 134, p. $503-514,1956$.

CARVAlHO, D. A Excursão Geográfica. Revista Brasileira de Geografia. Rio de Janeiro: ano III, nº 4, p. 864 - 873, 1941.

CARVAlHO, D. O Estudo da Paisagem. Boletim Geográfico. Rio de Janeiro: ano III, $n^{\circ}$ 32, p. 1049 - 1051, 1945.

CAVAlcAnti, A. P. B. Métodos e Técnicas da Análise Ambiental (Guia para estudos do meio ambiente). Teresina, UFPI/CCHL/DGH, 2006.

COSTA PEREIRA, J. V. Reflexões à margem de quatro excursões geográficas. Boletim Geográfico. Rio de Janeiro: ano I, no 5, p.7 14, 1943.

DAVID, C. Trabalho de campo: limites e contribuições para a pesquisa geográfica. GEO-UERJ - Revista do Departamento de Geografia. Universidade do Estado do Rio de Janeiro, Rio de Janeiro: $n^{\circ} 11$, p.19-24, 2002.

GUIMARÃES, F. M. S. Trabalhos de campo e de gabinete da segunda expedição geográfica ao Planalto Central. Revista Brasileira de Geografia. Rio de Janeiro: ano XI, n 4, p. 613 617, 1949. 
CAVALCANTI, A.P.B. Fundamentos históricos metodológicos da...

KAYSER, B. O geógrafo e a pesquisa de campo. Associação dos Geógrafos brasileiros (AGB), São Paulo, Seleção de Textos, Teoria e Método, $n^{\circ}$ 11, p. 25 - 40, 1985.

LACOSTE, Y. A pesquisa e o trabalho de campo; um problema político para os pesquisadores, estudantes e cidadãos. Associação dos Geógrafos brasileiros (AGB), São Paulo, Seleção de Textos, Teoria e Método, $\mathrm{n}^{\mathrm{o}}$ 11, p.1 - 23, 1985.

MACEDO, T. P. Roteiro de excursão à Araçatuba e Conjunto Hidrelétrico de Urubupungá. Orientação. São Paulo. IG Departamento de Geografia, USP, no 4, p. 31 - 33, 1969.

PRUNES, L. M. Plano de estudo de uma excursão geográfica. Boletim geográfico. Rio de Janeiro: ano I, nº 5, p. 63-67, 1943.

RADAELli DA SILVA, A. M. Trabalho de Campo: prática "andante" de fazer Geografia. Revista do Departamento de Geografia, Rio de Janeiro: nº 11, p. 61-74, 2002.

RODRIGUES, A. B.; OTAVIANO, C. A. Guia Metodológico de trabalho de campo em Geografia. Geografia, Londrina: v. 10, $\mathrm{n}^{\mathrm{o}} 1$, p. 35-43, 1991.

RUELLAN, F. O trabalho de campo nas pesquisas originais de Geografia Regional. Revista Brasileira de Geografia. Rio de Janeiro: ano VI, nº 1, p. 35 - 50, 1944.

SANTOS, R. J. Pesquisa empírica e trabalho de campo: algumas questões acerca do conhecimento geográfico. Sociedade \& Natureza, Uberlândia: 11, nº 21/22, p. 111 - 125, 1999.

SEABRA, M. Uma excursão aos arredores da cidade de São Paulo: área de Cotia - Vargem Grande. Orientação, São Paulo: IG Departamento de Geografia, USP, p. 26 - 32, 1965. 
CAVALCANTI, A.P.B. Fundamentos históricos metodológicos da...

SILVA, A. C. Natureza do trabalho de campo em Geografia Humana e suas limitações. Revista do Departamento de Geografia, São Paulo: Universidade de São Paulo, nº 1, p. 99-104, 1982.

STERNBERG, H. O' As listas de fatos a observar nos trabalhos geográficos de campo. Boletim Geográfico. Rio de Janeiro: ano IV, $n^{\circ} 40$, p. $456-465,1946$.

STERNBERG, H. O' O trabalho de campo na Geografia: seu planejamento e organização. Boletim Geográfico. Rio de Janeiro: ano II, n ${ }^{\circ}$ 49, p. 46 - 50, 1947.

VENTURI, L. A. B. (org.) Praticando Geografia - Técnicas de campo e laboratório. São Paulo: Oficina de Textos, 2005.

VIADANA, A. G. A excursão geográfica didática (Pontal do Triângulo Mineiro). Rio Claro: LPM - IGCE / UNESP, 2005.

SILVA, A. C. Natureza do trabalho de campo em Geografia Humana e suas limitações. Revista do Departamento de Geografia, São Paulo: USP, nº 1, p. 99-104, 1982.

Recebido em agosto de 2010 Aceito em junho de 2011 